Tohoku J. Exp. Med., 2005, 206, 131-139

\title{
Beneficial Effects of N-Acetylcysteine on Acetic Acid- Induced Colitis in Rats
}

\author{
Ali Cetinkaya, Ertan Bulbuloglu, ${ }^{1}$ Ergul Belge Kurutas, ${ }^{2}$ Harun Ciralik, ${ }^{3}$ \\ Bulent Kantarceken ${ }^{4}$ and Mehmet Akif Buyukbese \\ Department of Internal Medicine, ${ }^{1}$ Department of General Surgery, ${ }^{2}$ Depart- \\ ment of Biochemistry, ${ }^{3}$ Department of Pathology and ${ }^{4}$ Department of Gastroen- \\ terology, Medical Faculty, Sutcuimam University, Kahramanmaras, Turkey
}

Cetinkaya, A., Bulbuloglu, E., Kurutas, E.B., Ciralik, H., Kantarceken, B. and Buyukbese, M.A. Beneficial Effects of $N$-Acetylcysteine on Acetic Acid-Induced Colitis in Rats. Tohoku J. Exp. Med., 2005, 206 (2), 131-139 — Ulcerative colitis is a chronic recurrent inflammatory bowel disease in which oxidative stress has been implicated. The aim of the present study was to evaluate possible protective effects of $\mathrm{N}$-acetylcysteine against acetic acid-induced colitis in a rat model. Rats were administered intrarectal saline (control group) or acetic acid (colitis model group). Rats with acetic acid-induced colitis were treated by intraperitoneal or intrarectal administration of N-acetylcysteine $(500 \mathrm{mg} /$ $\mathrm{kg}$ ) (treated group). Another series of rats were pre-treated by intraperitoneal or intrarectal administration of $\mathrm{N}$-acetylcysteine, then administered intrarectal acetic acid (pre-treated group). The degree of tissue injuries was assessed by macroscopical and histopathological scores of the colonic mucosa. Malondialdehyde, myeloperoxidase, reduced glutathione, superoxide dismutase, and catalase levels were measured in tissue extracts of the dissected colon. Administration of N-acetylcysteine intraperitoneally or intrarectally ameliorated macroscopic score alterations produced by acetic acid in treated groups. In addition, microscopical improvement was observed in all $\mathrm{N}$-acetylcysteine-treated rats compared to untreated animals with colitis. In the colonic tissues of the acetic acid-induced colitis, myeloperoxidase activity and malondialdehyde levels were elevated, while the reduced glutathione levels and superoxide dismutase and catalase activities were decreased. However, intraperitoneal or intrarectal treatment with $\mathrm{N}$-acetylcysteine reversed these parameters, compared to the untreated colitis group. Notably, intrarectal administration of N-acetylcysteine elevated the reduced glutathione levels more markedly compared to the other treatment groups. Superoxide dismutase levels were increased in intraperitoneally or intrarectally $\mathrm{N}$-acetylcysteine-treated groups significantly compared to the control, colitis and pre-treated groups. But there was no significant increase in catalase activity. In conclusion, $\mathrm{N}$-acetylcysteine could be beneficial as a complementary agent in treatment of ulcerative colitis. $-\mathrm{N}$-acetylcysteine; colitis; reactive oxygen species; acetic acid; GSH (C) 2005 Tohoku University Medical Press

Received October 13, 2004; revision accepted for publication March 18, 2005.

Correspondence: Ali Cetinkaya, KSU Tip Fakultesi, Ic Hastaliklari AD, Kahramanmaras, Turkey.

e-mail: drcetinkaya@yahoo.com, alicetinkaya@ksu.edu.tr 
Ulcerative colitis is a chronic inflammatory disease of the colon and rectum. While the exact cause remains unknown, possible etiological factors, including genetic, immunologic, and enviromental, have been implicated (Kirsner and Shorter 1982; Jewell and Patel 1985). Recently, the altered oxidant/antioxidant status in the inflamed colon has received attention in both humans and animals. Evidence suggests that reactive oxygen species (ROS), hypochlorous acid and oxidant derivatives are produced in excess by the inflamed mucosa and may be pathogenic in inflammatory bowel disease (IBD) (Keshavarzian et al. 1990; Grisham 1994; Millar et al. 1996). The main sources of ROS in the inflamed mucosa are activated phagocytic leukocytes and neutrophils, capable of producing superoxide and cascade of various reactive species leading to a very reactive hydroxyl radical and peroxide. These products cause the impairment in cell membrane stability and death of the cells by lipid peroxidation in IBD (Fantone and Ward 1982; Flohe et al. 1985; Buffinton and Doe 1995). Those intermediate products of oxygen metabolism (i.e., superoxide, hydroxyl radicals, and $\mathrm{H}_{2} \mathrm{O}_{2}$ ) are controlled by various cellular defense mechanisms comprising enzymatic (i.e., superoxide dismutase and catalase) and non-enzymatic (GSH) scavenger components.

Increased oxidative stress and decreased antioxidant defenses have been demonstrated in colonic mucosal biopsies of the patients with IBD (Lih-Brody et al. 1996). It has been suggested that the imbalance between prooxidant and antioxidant mechanisms in IBD may be controlled by antioxidant treatment. Some agents have already proved effective in experimental conditions, the antioxidants such as vitamin E, selenium and trimetazidine were found to be beneficial in ulcerative colitis models. (Yoshida et al. 1999; Kuralay et al. 2003; Ademoglu et al. 2004).

$\mathrm{N}$-acetylcysteine (NAC) has been widely used as an antioxidant in vivo and in vitro (Moldeus et al. 1986; Ziment 1986; Junod et al. 1987). It is also efficient in the treatment of some drug overdosage, e.g., acetaminophen and drug overuse (Prescott et al. 1979). NAC is known to act by raising intracellular concentrations of cysteine and hence of GSH and/or by scavenging (De Vries and De Flora 1993).

The aim of the present study was to determine if NAC was effective in the treatment of rat model of ulcerative colitis, an oxidant-mediated disorder. Several animal models of colitis have been described. One of those, acetic acid-induced colitis is a reproducible and simple model, sharing many characteristics with human colitis (MacPherson and Pfeiffer 1978). We utilized this model of colitis to evaluate the effect of NAC on tissue damage and colonic inflammation.

\section{Materials and Methods}

Animals

Male Wistar-Albino rats (Kahramanmaras Sutcu imam University School of Medicine Experimental Research Laboratory, Kahramanmaras, Turkey) weighing 200-230 g, were used. The animals were housed under a $12 \mathrm{~h}$ light/dark cycle (lights on from $08.00 \mathrm{~h}$ ) at a constant ambient temperature $\left(21-22^{\circ} \mathrm{C}\right)$, with normal rat chow and water ad libitum. The structure of this study and animal experimental procedures were approved by the Ethical Committee of Kahramanmaras Sutcu Imam University School of Medicine. All rats were fasted $24 \mathrm{~h}$ prior to the experimental procedure.

\section{Acute colitis induction and treatment protocols}

Colitis was induced in rats by intrarectal (IR) administration of $1 \mathrm{ml}$ of $4 \%$ acetic acid (AA). After ether anesthesia, a soft $6 \mathrm{~F}$ pediatric catheter was introduced into the anus for $6 \mathrm{~cm}$ and AA was carefully administered. Before taking the catheter out, $2 \mathrm{ml}$ air was applied in order to spread AA completely in the colon. As previously shown, an intrarectal administration of $4 \%$ AA produces colonic inflammation in rats that resembles many histological characteristics of human ulcerative colitis (Choudhary et al. 2001) (Fig. 1).

On the other hand, NAC (Bilim-Istanbul) $500 \mathrm{mg} /$ $\mathrm{kg}$ was administered in a $1 \mathrm{ml}$ volume by intraperitoneal (IP) and / or intrarectal (IR) route.

The rats were divided into six groups;

Control $(n=10)$ : IR saline was administered after the IP administration of saline.

Colitis Model $(n=10)$ : IR AA was administered $1 \mathrm{~h}$ after the IP administration of saline.

Pre-treated-NAC-IP $(n=10)$ : IR AA was adminis- 
tered $1 \mathrm{~h}$ after the IP administration of NAC.

Pre-treated-NAC-IR $(n=9)$ : IR AA administered $1 \mathrm{~h}$ after the IR administration of NAC.

Treated-NAC-IP $(n=8)$ : IP NAC administered $24 \mathrm{~h}$ after the IR administration of AA.

Treated-NAC-IR $(n=10)$ : IR NAC administered $24 \mathrm{~h}$ after the IR administration of AA.

\section{Assessment of the colonic damage}

Rats were sacrificed after 24 hours following the NAC-treatment in treated groups and after 48 hours in the other groups. Under general anesthesia, all rats were sacrificed by cervical decapitation. The abdomen was opened and the colon was exposed. The distal $8 \mathrm{~cm}$ of the colon was excised and opened by a longitudinal incision. After washing the mucosa with saline solution, mucosal injury (macroscopically) was assessed using the grading scale of Morris et al. (1989). No damage (score 0 ), localized hyperemia but no ulcers (score 1); linear ulcers with no significant inflammation (score 2); linear ulcer with inflammation at one site (score 3); two or more sites of ulceration and inflammation (score 4); two or more sites of ulceration and inflammation or one major site of inflammation and ulceration extending $>1 \mathrm{~cm}$ along the length of the colon (score 5). Additional samples were preserved in $10 \%$ formalin for histological examination. Formalin-fixed colonic samples were embedded in paraffin, and sections were stained with H\&E. The degree of inflammation of the colon was graded semiquantitatively from 0 to 11 according to described criteria (1) loss of mucosal architecture (score 0-3), (2) cellular infiltration (score 0-3) (3) muscle thickening (score 0-3), (4) crypt abscess formation (score $0-1)$ and (5) goblet cell depletion (score 0-1) (Appleyard and Wallace 1995).

After scoring colonic tissue samples were homogenized with 10 volumes of ice-cold $0.25 \mathrm{M}$ sucrose, centrifugated at $14,000 \mathrm{rpm}$ to measure the biochemical parameters in resulting supernatant.

\section{Colonic myeloperoxidase activity}

Colonic Myeloperoxidase (MPO) activity was determined by a modification of the O-dianisidine method (Worthington Biochemical Corporation 1972). The assay mixture, in a cuvette of $1 \mathrm{~cm}$ path length, contained 0.3 $\mathrm{ml} 0.1 \mathrm{M}$ phosphate buffer ( $\mathrm{pH} 6.0$ ), $0.3 \mathrm{ml} 0.01 \mathrm{M} \mathrm{H}_{2} \mathrm{O}_{2}$, $0.5 \mathrm{ml} 0.02 \mathrm{M}$ O-dianisidine (freshly prepared) in deionized water and $10 \mu 1$ supernatant in a final volume of 3.0 $\mathrm{ml}$. The supernatant was added at last and the change in absorbance at $460 \mathrm{~nm}$ was followed for $10 \mathrm{~min}$. All measurements were carried out in duplicate. One unit of MPO was defined as that giving an increase in absorbance of 0.001 per min and specific activity was given as units/mg protein.

\section{Lipid peroxidation determination}

Lipid peroxidation level in the tissue samples was assessed by measuring malondialdehyde (MDA). MDA was measured according to the procedure of Ohkawa et al. (1979). The reaction mixture contained $0.1 \mathrm{ml}$ tissue sample, $0.2 \mathrm{ml}$ of $8.1 \%$ sodium dodecyl sulphate (SDS), $1.5 \mathrm{ml}$ of $20 \%$ acetic acid and $1.5 \mathrm{ml}$ of $0.8 \%$ aqueous solution of thiobarbituric acid. The mixture $\mathrm{pH}$ was adjusted to 3.5 and volume was finally made up to $4.0 \mathrm{ml}$ with distilled water and $5.0 \mathrm{ml}$ of the mixture of n-butanol and pyridine $(15: 1, \mathrm{v} / \mathrm{v})$ was added. The mixture was shaken vigorously. After centrifugation at 4,000 rpm for $10 \mathrm{~min}$, the absorbance of the organic layer was measured at $532 \mathrm{~nm}$. MDA level was expressed as $\mathrm{nmol} / \mathrm{mg}$ protein.

\section{Assessment of antioxidant status in colonic tissues}

Reduced glutathione (GSH) level was determined according to Beutler (1975). The reaction mixture contained filtrate, phosphate buffer and DTNB (5, $5^{\prime}$-dithiobis 2-nitrobenzoic acid) in a final volume of $10 \mathrm{ml}$. A blank was also prepared by using precipitating reagent and distilled water instead of filtrate. The absorbances were immediately read in a spectrophotometer at $412 \mathrm{~nm}$ before and after addition of DTNB. The values were determined from the standard curve. GSH level was expressed as $\mu \mathrm{mol} / \mathrm{mg}$ protein. Superoxide dismutase (SOD) activity was measured according to the method described by Fridovich (1983). This method employs xanthine and xanthine oxidase to generate superoxide radicals which react with $\mathrm{p}$-iodonitrotetrazlium violet (INT) to form a red formazan dye which was measured at $505 \mathrm{~nm}$. Assay medium consisted $0.01 \mathrm{M}$ phosphate buffer, CAPS (3-cyclohexilamino-1-propanesulfonicacid) buffer solution (50 mM CAPS, $0.94 \mathrm{mM}$ EDTA, satd. $\mathrm{NaOH})$ with $\mathrm{pH} 10.2$, solution of substrate $(0.05 \mathrm{mM}$ xanthine, $0.025 \mathrm{mM} \mathrm{INT}$ ) and 80 UL xanthine oxidase. SOD activity was expressed as U/mg protein. Catalase (CAT) activities were determined by measuring the decrease in hydrogen peroxide concentration at $230 \mathrm{~nm}$ by the method of Beutler (1975). Assay medium consisted $1 \mathrm{M}$ Tris HCI, $5 \mathrm{mM} \mathrm{Na}_{2}$ EDTA buffer solution ( $\mathrm{pH} 8.0$ ), $1 \mathrm{M}$ phosphate buffer solution ( $\mathrm{pH} 7.0$ ), and $10 \mathrm{mM}$ 
$\mathrm{H}_{2} \mathrm{O}_{2}$. CAT activity was expressed as U/mg protein.

The protein concentration of tissue samples was measured with Spectronic-UV 120 spectrophotometer by the method of Lowry et al. (1951).

All chemicals were obtained from the Sigma Chemical Corporation (St. Louis, MO, USA) with the exception of $\mathrm{N}$-acetylcysteine which was from Bilim (Husnu Arsan Drug Company, Istanbul, Turkey).

\section{Statistical analyses}

Nonparametric statistics were used to evaluate the results. Data were subjected to the Mann Whitney's U-test, where values were considered to be significant according to the Bonferroni correction. For all analyses, an associated probability ( $p$ value) of 0.05 or less was considered statistically significant.

\section{RESULTS}

IR administration of $4 \%$ AA, extensive macroscopic damage of the rat colon was observed. (Fig. 1). The colonic mucosa appeared hemorrhagic and ulcerated. When the macroscopic scores of the colitis model group were compared to those of other groups (Table 1), the lowest macroscopic scores were observed in rats which belonged to treated-NAC (IP and IR) groups, and this difference was statistically significant. Even though IP administered NAC reduced the scores more, there was no marked difference between IP and IR route. Pre-treated NAC administration did not produce any significant difference compared to untreated colitis group (Table 1). The colonic damage as determined histologically paralleled to that of macroscopically visible damage. Wide areas of epithelial and goblet cell loss and marked

Fig. 1. Representative histological slides from rats receiving saline enema (control, $\mathrm{A}$ ), acetic acid (colitis, B), acetic acid and $\mathrm{N}$-acetylcysteine $500 \mathrm{mg} / \mathrm{kg}$ (treated-NAC-IP, C). The colon was cut, embedded in paraffin and then stained with H\&E $(\times 50)$. Note the distortion of crypt architecture, cryptit and crypt abscess (arrowheads), loss of epithelial cells with ulceration (arrows), and goblet cell depletion with neutrophil infiltration (bold arrows) in acetic acid treated rats (B). The histological changes were significantly improved by $\mathrm{N}$-acetylcysteine therapy as seen in a sample from treated-NACIP group (C). Scale bars indicate $100 \mu \mathrm{m}$. inflammatory cell infiltration, ulcers, cryptit and crypt abscesses were observed in the colon specimens of AA-treated rats (Fig. 1B). NAC improved the microscopic scores in all treatment groups compared to colitis model group. Although the best microscopical improvement was observed in pre-treated IR NAC group
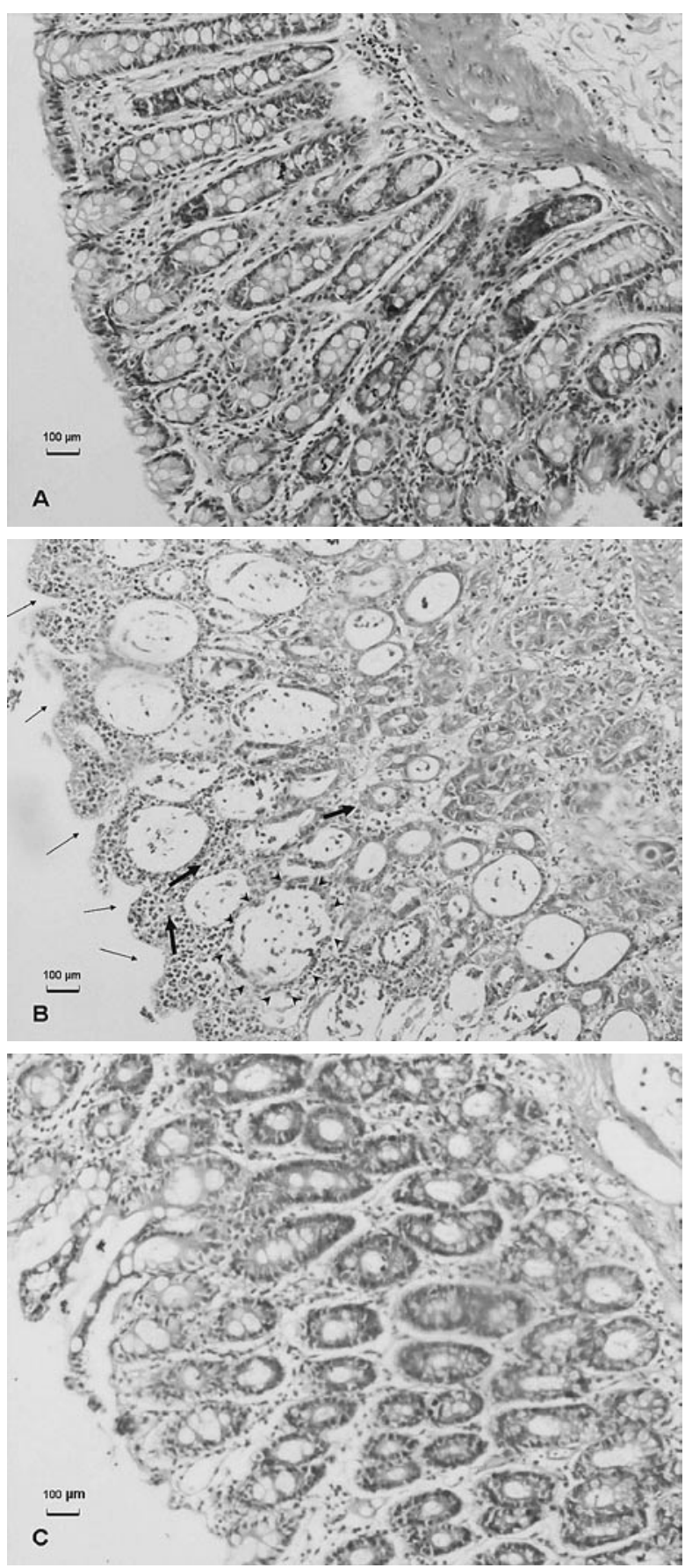
TABLE 1. Effect of NAC on AA-induced changes in histopathologic and biochemical parameters

\begin{tabular}{lcccccc}
\hline & $\begin{array}{c}\text { Control } \\
(n=10)\end{array}$ & $\begin{array}{c}\text { Colitis Model } \\
(n=10)\end{array}$ & $\begin{array}{c}\text { Pre-treated- } \\
\text { NAC-IP } \\
(n=10)\end{array}$ & $\begin{array}{c}\text { pre-treated- } \\
\text { NAC-IR } \\
(n=9)\end{array}$ & $\begin{array}{c}\text { Treated- } \\
\text { NAC-IP } \\
(n=8)\end{array}$ & $\begin{array}{c}\text { Treated- } \\
\text { NAC-IR } \\
(n=10)\end{array}$ \\
\hline $\begin{array}{l}\text { Macroscopic score } \\
\text { Histopathologic }\end{array}$ & $\mathrm{ND}$ & $4.50 \pm 0.52^{\mathrm{a}}$ & $3.80 \pm 1.03$ & $3.40 \pm 1.77$ & $2.00 \pm 1.60$ & $2.55 \pm 1.13$ \\
score & $0.1 \pm 0.31$ & $7 \pm 0.47^{\mathrm{b}}$ & $4.40 \pm 1.77$ & $3.33 \pm 1.41$ & $4.50 \pm 1.51$ & $4.15 \pm 2.54$ \\
$\begin{array}{l}\text { MDA } \\
\text { (nmol/mg protein) }\end{array}$ & $7.95 \pm 0.53^{\mathrm{c}}$ & $20.06 \pm 1.62^{\mathrm{b}}$ & $13.79 \pm 2.83$ & $13.99 \pm 1.56$ & $11.09 \pm 1.42$ & $11.40 \pm 1.31$ \\
$\begin{array}{l}\text { SOD } \\
\text { (U/mg protein) }\end{array}$ & $5.42 \pm 0.86$ & $4.27 \pm 0.97$ & $4.83 \pm 0.65$ & $6.12 \pm 1.36$ & $8.77 \pm 0.94^{\mathrm{d}}$ & $10.18 \pm 0.97^{\mathrm{d}}$ \\
$\begin{array}{l}\text { CAT } \\
(\mathrm{U} / \mathrm{mg} \text { protein) }\end{array}$ & $23.97 \pm 1.83^{\mathrm{c}}$ & $11.38 \pm 0.88$ & $8.92 \pm 0.57$ & $10.56 \pm 1.29$ & $18.46 \pm 1.41^{\mathrm{e}}$ & $14.18 \pm 1.52^{\mathrm{d}}$ \\
\hline
\end{tabular}

Data are presented as mean \pm S.D. ND, non-damage; AA, acetic acid; NAC, N-acetylcysteine;

MDA, malondialdehyde; SOD, superoxide dismutase and CAT, catalase.

${ }^{a} p<0.05$ vs treated-NAC-IP and treated-NAC-IR rats.

${ }^{\mathrm{b}} p<0.05$ vs control, pre-treated-NAC and treated-NAC rats.

${ }^{\mathrm{c}} p<0.05$ vs colitis model, pre-treated-NAC and treated-NAC rats.

${ }^{\mathrm{d}} p<0.05$ vs control, colitis model and pre-treated-NAC rats.

${ }^{\mathrm{e}} p<0.05$ vs control, colitis model, pre-treated-NAC and treated-NAC-IR rats.

as seen in Table 1, there was no significant difference with the other treatment groups. Regenerated epithelium is seen in Fig. 1C obtained from a specimen of treated-NAC-IP group. AA also caused significant neutrophil infiltration into the colonic mucosa (Fig. 1B) and colonic MPO activity, which is a marker of inflammation, significantly increased in colitis model group (Fig.
2). However, treatment with NAC significantly reduced MPO activities compared to colitis model group (Fig. 2). While the values of MPO activity closest to control group was determined in IP and IR treated-NAC groups, it was shown in Figure 2 that they were significantly different from pretreated NAC groups.

To examine the oxidative stress in AA-

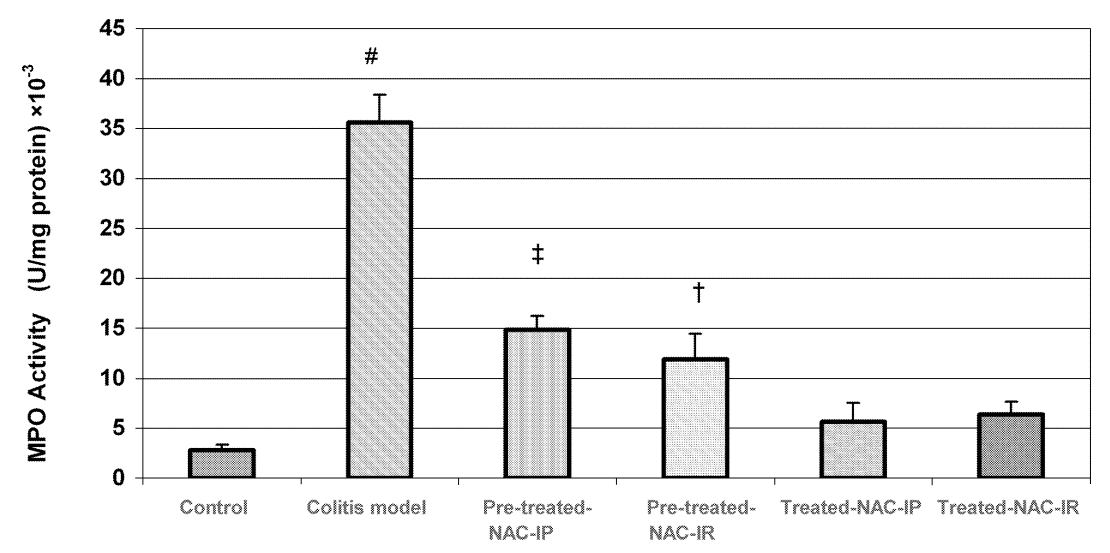

Fig. 2. MPO activity of colonic mucosa in experimentally induced colitis model. Data are mean \pm S.D. of 8-10 rats per group. \#, colitis model group significantly different from all groups $(p<0.001)$; , pre-treated-NAC-IP group different from treated-NAC-IP and pre-treated-NAC-IR groups $(p<$ $0.001), \dagger$, pre-treated-NAC-IR group different from treated-NAC-IP and treated-NAC-IR groups $(p$ $<0.05)$. The values in $\mathrm{Y}$ axis are expressed as being multiplied by $10^{-3}$. 


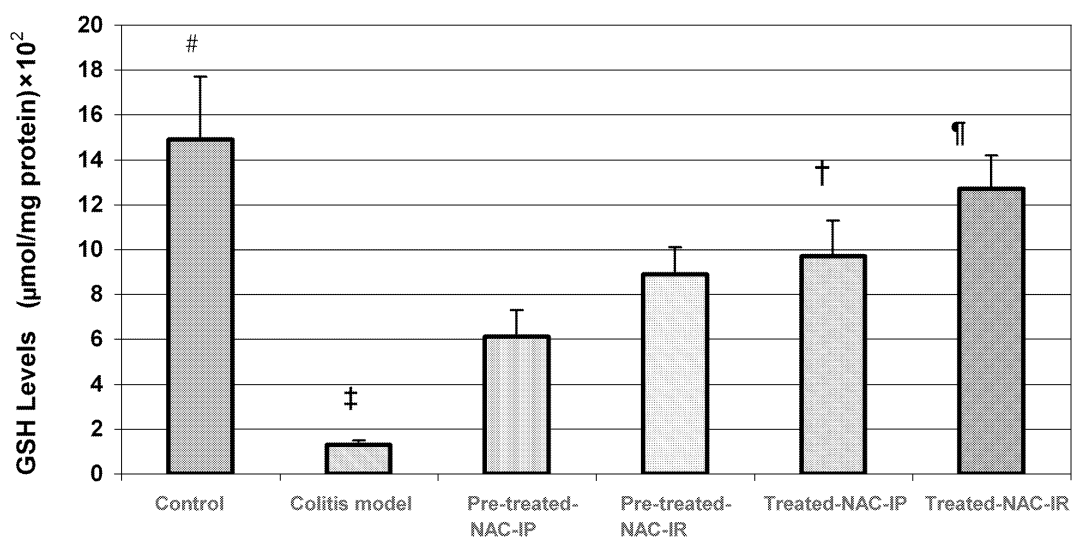

Fig. 3. Effect of NAC on the level of GSH measured in the rat colon of AA-induced colitis. Values are means \pm S.D. \#, control group is significantly different from groups, pre-treated-NAC and treatedNAC-IP $(p<0.001)$. $\ddagger$, colitis model group is significantly different from groups control, pre-treated and treated-NAC groups $(p<0.001)$. $\dagger$, treated-NAC-IP group is also significantly different from treated-NAC-IR group $(p<0.05)$. I, treated-NAC-IR group is significantly different from groups colitis model, pre-treated-NAC and treated-NAC-IP $(p<0.001)$. The values in Y axis are expressed as being multiplied by $10^{2}$.

induced colitis we determined the levels of MDA in the colon homogenates of rats. AA administration significantly elevated the levels of MDA in comparison with controls (Table 1). However, NAC administration to the AA-treated rats significantly reduced the MDA levels in all treatment groups compared to untreated colitis group (Table 1). The levels of MDA closest to untreated control group were in treated-NAC (IP and IR) groups. However, no significant difference was observed with pre-treated NAC groups in view of MDA levels (Table 1).

In comparison with the controls, there were significantly lower levels of GSH in colons with AA-induced damage. Pre-treatment as well as treatment with NAC prevented the depletion of GSH caused by AA compared to colitis model group. Nevertheless, treated-NAC-IR group was found out to be more effective in preventing the depletion of GSH levels in comparison with the other groups (Fig. 3). Data in Table 1 also demonstrate that AA administration lowered the antioxidant enzyme SOD activity. NAC treatment significantly enhanced SOD activity except in the pre-treated NAC groups (IP and IR) compared to control and colitis model groups (Table 1). CAT activity significantly decreased by the effect of
AA was seen to be increased in treated-NAC (IP and IR) groups however, this increase could not reach to the activity in controls (Table 1).

\section{Discussion}

NAC administration (IP and IR routes) prove to induce improvements in various parameters of colonic inflammation, i.e., macroscopic and histopathologic score of colonic damage and tissue MPO activity. MPO is an enzyme found predominantly in neutrophils and has been used as an effective quantitative index of inflammation due to the correlation between MPO activities and the histological analysis of neutrophil infiltration of the colon (Krawisz et al. 1984; Sekikuza et al. 1988). Microscopic evaluation in our study also included an increased number of neutrophil leukocytes, which possibly contributed to elevated MPO activity observed in AA-induced colitis.

In our study, IP and IR given NAC after AA (treated groups) was shown to significantly decrease gross mucosal injury caused by AA. On the other hand, pre-treated NAC could not provide a marked improvement on macroscopical score. This beneficial effect of NAC on macroscopical score supports the results reported by Nosal'ova et al. that locally applied NAC 
reduced the mucosal injury in experimental colitis induced by AA (Nosal'ova et al. 2000). Furthermore, obvious microscopical improvement was obtained in our study in all NAC treatment groups compared to colitis model group. Colonic MPO activities also decreased significantly in all treatment groups parallel to histopathological changes (more significant especially in treatedNAC-IP and IR groups). These findings suggest that NAC treatment had beneficial effects by reducing the severity of colonic inflammation.

Many antioxidant agents have been investigated to prevent the colitis due to oxidant exposure e.g., Zolimid and AEOL11201 (Choudhary et al. 2001), L-glutamine (Kaya et al. 1999), melatonin (Pentney and Bubenik 1995) and ascorbat (Simmonds et al. 1999). Also, beneficial effects of a polysaccharide "angelica sinensis" have been reported in trinitrobenzene sulfonic acid (TNBS) and ethanol-induced experimental colitis (Liu et al. 2003).

NAC appears to support the synthesis of GSH, primarly under conditions when the demand for GSH is increased, such as during excessive oxidative stress, or during certain disease processes. Most of the beneficial effects of NAC are suggested as being a result of its ability to either reduce extracellular cystine to cysteine, or to be a source of thiol $(\mathrm{SH})$ metabolites. As a source of SH groups, NAC stimulates glutathione synthesis, enhances glutathione-S-transferase activity, and acts on reactive oxidant radicals (De Vries and De Flora 1993). NAC was also found to be a powerful scavenger of hypochlorous acid ( $\mathrm{HOCl})$. $\mathrm{HOCl}$, produced by the action of MPO on hydrogen peroxide in the presence of chloride ions, is importantly involded in the inflammatory reaction in colitis and its scavenging may thus account for observed protective effect of NAC.

The protective roles of glutathione and GSHdependent enzymes were documented against noxius compounds in the gastrointestinal tract (Siegers et al. 1988). Evidence from various pathological and toxicological conditions such as ischemia-reperfusion, chemically induced oxidative injury, aging and degenerative disease, indicate that GSH is a primary component of the pro- tection system of the cells against oxidative and free radical mediated cell damage (Shan et al. 1990).

In our study, NAC prevented the depletion of GSH caused by AA administration either in pretreated or treated groups compared to colitis model group, as expected. Data in this study support the view that NAC has beneficial effect on GSH level in colonic injury (Ardite et al. 2000; Nosal'ova et al. 2000). Moreover, treated-NACIR was demonstrated to protect the levels of GSH more effectively than the other treatment groups against the harmful effect of AA.

On the other hand, results of the studies examining the status of the antioxidant enzymes e.g., SOD and CAT, in ulcerative colitis (UC) are controversial. Kuralay et al. (2003) reported the markedly increased activities of SOD, but not different CAT activities in AA-induced colitis. Beno et al. (1994, 1996) also found markedly elevated antioxidant enzyme activities such as SOD and CAT in IBD. On the contrary, Dong et al. (2003) showed a significant decrease in tissue SOD levels in AA-induced colitis. They also found an increase of SOD levels in treatment groups compared to colitis model group. Liu et al. (2003) obtained similar results according to SOD levels in TNBS plus ethanol induced experimental colitis as well. On the other hand, SOD levels decreased by the effect of AA were shown to be increased in our study following NAC treatment in accordance with the studies mentioned above. Although this increase was significantly higher in both treated-NAC groups compared to colitis model and control groups, no significant increase was observed in pre-treated groups. Marked increase in CAT activity, however, could not be obtained.

Toxic colitic injury has been shown to increase MDA levels in rats and on the contrary various agents used in the treatment of the disease were shown to decrease it (Paiva et al. 2002; Liu et al. 2003; Mahgoub et al. 2003). In addition, NAC was also shown to decrease the levels of MDA in studies in which experimental damage was formed other than colitis (Aydin et al. 2002; Ozaras et al. 2003; Park et al. 2003). In this 
study, MDA was also found to be decreased significantly in all treatment groups compared to AA group. The decrease was more evident especially in treated-NAC groups.

Our findings indicate that the NAC administration intraperitoneally or intrarectally to the rats with AA-induced colitis can reduce the extent of colonic mucosal injury, attenuate the increase in MPO activity and MDA levels, and restore diminished antioxidant enzymes and substance such as SOD, CAT and GSH; thus NAC protects the colon from AA-induced lipid peroxidation. Our data also suggest that NAC is more effective when given after the induction of colitis.

In conclusion, NAC could be beneficial as a complementary agent in ulcerative colitis treatment. Large scale studies in humans would be definitely beneficial in elucidating the effects of antioxidants in ulcerative colitis more clearly.

\section{References}

Ademoglu, E., Erbil, Y., Tam, B., Barbaros, U., Ilhan, E., Olgac, V. \& Mutlu-Turkoglu, U. (2004) Do vitamin E and selenium have beneficial effects on trinitrobenzenesulfonic acidinduced experimental colitis. Dig. Dis. Sci., 49, 102-108.

Appleyard, C.B. \& Wallace, J.L. (1995) Reactivation of hapteninduced colitis and its prevention by anti-inflammatory drugs. Am. J. Physiol., 269, G119-G125.

Ardite, E., Sans, M., Panes, J., Romero, F.J., Pique, J.M. \& Fernandez-Checa, J.C. (2000) Replenishment of glutathione levels improves mucosal function in experimental acute colitis. Lab. Invest., 80, 735-744.

Aydin, S., Ozaras, R., Uzun, H., Belce, A., Uslu, E., Tahan, V., Altug, T., Dumen, E. \& Senturk, H. (2002) N-acetylcysteine reduced the effect of ethanol on antioxidant system in rat plasma and brain tissue. Tohoku J. Exp. Med., 198, 71-77.

Beno, I., Staruchova, M., Volkovova, K., Mekinova, D., Bobek, P. \& Jurcovicova, M. (1994) Activity of the antioxidant system in patients with idiopathic proctocolitis and the effect of 5-aminosalicylic acid (Salofalk). Bratisl. Lek. Listy., 95, 99-102.

Beno, I., Staruchova, M., Batovsky, M. \& Volkovova, K. (1996) Adenomatous and inflammatory colorectal polyps: antioxidative enzyme activity in the colon. Cas. Lek. Cesk., 135, 208-210.

Beutler, E. (1975) Red Cell Metabolism. 2nd ed., Grune and Stratton Company, New York.

Buffinton, G.D. \& Doe, W.F. (1995) Depleted mucosal antioxidant defences in inflammatory bowel disease. Free. Radic. Biol. Med., 19, 911-918.

Choudhary, S., Keshavarzian, A., Yong, S., Wade, M., Bocckino, S., Day, B.J. \& Banan, A. (2001) Novel antioxidants zolimid and AEOL11201 ameliorate colitis in rats. Dig. Dis. Sci., 46, 2222-2230.

De Vries, N. \& De Flora, S. (1993) N-Acetyl-1-Cysteine. J.
Cell Biochem., 17F, 270-277.

Dong, W.G., Liu, S.P., Yu, B.P., Wu, D.F., Luo, H.S. \& Yu, J.P. (2003) Ameliorative effects of sodium ferulate on experimental colitis and their mechanisms in rats. World. J. Gastroenterol., 9, 2533-2538.

Fantone, J.C. \& Ward, P.A. (1982) Role of oxygen-derived free radicals and metabolites in leukocyte-dependent inflammatory reactions. Am. J. Pathol., 107, 395-418.

Flohe, L., Beckmann, R., Giertz, H. \& Loschen, G. (1985) Oxygen-centered free radicals as mediators of inflammation. In: Oxidative Stress, edited by $\mathrm{H}$. Sies, Academic Press, London, pp. 403-436.

Fridovich, I. (1983) Superoxide radical: an endogenous toxicant. Annu. Rev. Pharmacol. Toxicol., 23, 239-257.

Grisham, M.B. (1994) Oxidants and free radicals in inflammatory bowel disease. Lancet, 344, 859-861.

Jewell, D.P. \& Patel, C. (1985) Immunology of inflammatory bowel disease. Scan. J. Gastroenterol., 114, Suppl., 119-126.

Junod, A.F., Jornot, L. \& Grichting, G. (1987) Comparative study on the selenium and $\mathrm{N}$-acetylcysteine-related effects on the toxic action of hyperoxia, paraquat and the enzyme reaction hypoxanthine-xanthine oxidase in cultured endothelial cells. Agents Actions, 22, 176-183.

Kaya, E., Gur, E.S., Ozguc, H., Bayer, A. \& Tokyay, R. (1999) L-glutamine enemas attenuate mucosal injury in experimental colitis. Dis. Colon Rectum, 42, 1209-1215.

Keshavarzian, A., Morgan, G., Sedghi, S., Gordon, J.H. \& Doria, M. (1990) Role of reactive oxygen metabolites in experimental colitis. Gut, 31, 786-790.

Kirsner, J.B. \& Shorter, R.G. (1982) Recent developments in "nonspecific" inflammatory bowel disease (first of two parts). N. Engl. J. Med., 306, 775-785.

Kirsner, J.B. \& Shorter, R.G. (1982) Recent developments in "nonspecific" inflammatory bowel disease (second of two parts). N. Engl. J. Med., 306, 837-848.

Krawisz, J.E., Sharon, P. \& Stenson, W.F. (1984) Quantitative assay for acute intestinal inflammation based on myeloperoxidase activity. Gastroenterology, 87, 1344-1350.

Kuralay, F., Yildiz, C., Ozutemiz, O., Islekel, H., Caliskan, S., Bingol, B. \& Ozkal, S. (2003) Effects of trimetazidine on acetic acid-induced colitis in female swiss rats. J. Toxicol. Environ. Health A, 66, 169-179.

Lih-Brody, L., Powell, S.R., Collier, K.P., Reddy, G.M., Cerchia, R., Kahn, E., Weissman, G.S., Katz, S., Floyd, R.A., McKinley, M.J., Fisher, S.E. \& Mullin, G.E. (1996) Increased oxidative stres and decreased antioxidant defences in mucosa of inflammatory bowel disease. Dig. Dis. Sci., 41, 2078-2086.

Liu, S.P., Dong, W.G., Wu, D.F., Luo, H.S. \& Yu, J.P. (2003) Protective effect of angelica sinensis polysaccharide on experimental immunological colon injury in rats. World $J$. Gastroenterol., 9, 2786-2790.

Lowry, O.H., Rosebrough, N.J., Farr, A.L. \& Randall, R.J. (1951) Protein measurement with the Folin phenol reagent. Biol. Chem., 193, 265-275.

MacPherson, B.R. \& Pfeiffer, C.J. (1978) Experimental production of diffuse colitis in rats. Digestion, 17, 135-150.

Mahgoub, A.A., El-Medany, A.A., Hager, H.H., Mustafa, A.A. \& El-Sabah, D.M. (2003) Evaluating the prophylactic potential of zafirlukast against the toxic effects of acetic acid on the rat colon. Toxicol. Lett., 145, 79-87.

Millar, A.D., Rampton, D.S., Chander, C.L., Claxson, A.W., Blades, S., Coumbe, A., Panetta, J., Morris, C.J. \& Blake, 
D.R. (1996) Evaluating the antioxidant potential of new treatments for inflammatory bowel disease using a rat model of colitis. Gut, 39, 407-415.

Moldeus, P., Cotgreave, I.A. \& Berggren, M. (1986) Lung protection by a thiolcontaining antioxidant: $\mathrm{N}$-acetylcysteine. Respiration, 50, Suppl. 1, 31-42.

Morris G.P., Beck, P.L., Herridge, M.S., Depew, W.T., Szewczuk, M.R. \& Wallace, J.L. (1989) Hapten-induced model of chronic inflammation and ulceration in the rat colon. Gastroenterology, 96, 795-803.

Nosal'ova, V., Cerna, S. \& Bauer, V. (2000) Effect of N-acetylcysteine on colitis induced by acetic acid in rats. Gen. Pharmacol., 35, 77-81.

Ohkawa, H., Ohishi, N. \& Yagi, K. (1979) Assay for lipid peroxides in animal tissues by thiobarbituric acid reaction. Anal. Biochem., 95, 351-358.

Ozaras, R., Tahan, V., Aydin, S., Uzun, H., Kaya, S. \& Senturk, H. (2003) N-acetylcysteine attenuates alcohol-induced oxidative stess in rats. World. J. Gastroenterol., 9, 791-794.

Paiva, L.A., Gurgel, L.A., Silva, R.M., Tome, A.R., Gramosa, N.V., Silveira, E.R., Santos, F.A. \& Rao, V.S. (2002) Antiinflammatory effect of kaurenoic acid, a diterpene from Copaifera langsdorffi on acetic acid-induced colitis in rats. Vascul. Pharmacol., 39, 303-307.

Park, E.S., Kim, S.D., Lee, M.H., Lee, H.S., Lee, I.S., Sung, J.K. \& Yoon, Y.S. (2003) Protective effects of N-acetylcysteine and selenium against doxorubicin toxicity in rats. J. Vet. Sci., 4, 129-136.

Pentney, P.T. \& Bubenik, G.A. (1995) Melatonin reduces the severity of dextran-induced colitis in mice. J. Pineal. Res.,
19, 31-39.

Prescott, L.F., Illingworth, R.N., Critchley, J.A., Stewart, M.J., Adam, R.D. \& Proudfoot, A.T. (1979) Intravenous N-acetylcysteine: the treatment of choice for paracetamol poisoning. Br. Med. J., 2, 1097-1100.

Sekizuka, E., Grisham, M.B., Li, M.A., Deitch, E.A. \& Granger, D.N. (1988) Inflammation induced intestinal hyperemia in the rat: Role of neutrophils. Gastroenterology, 95, 1528-1534.

Shan, X.Q., Aw, T.Y. \& Jones, D.P. (1990) Glutathione-dependent protection against oxidative injury. Pharmacol. Ther., 47, 61-71.

Siegers, C.P., Riemann, D., Thies, E. \& Younes, M. (1988) Glutathione and GSH-dependent enzymes in the gastrointestinal mucosa of the rat. Cancer Lett., 40, 71-76.

Simmonds, N.J., Millar, A.D., Blake, D.R. \& Rampton, D.S. (1999) Antioxidant effects of aminosalicylates and potential new drugs for inflammatory bowel disease: assessment in cell-free systems and inflamed human colorectal biopsies. Aliment. Pharmacol. Ther., 13, 363-372.

Worthington Biochemical Corporation (1972) Worthington Enzyme Manual. Freehold, N.J.

Yoshida, N., Yoshikawa, T., Yamaguchi, T., Naito, Y., Tanigawa, T., Murase, H. \& Kondo, M. (1999) A novel water soluble vitamin E derivative protects againts experimental colitis in rat. Antioxid. Redox. Signal., 1, 555-562.

Ziment, I. (1986) Acetylcysteine: a drug with an interesting past and a fascinating future. Respiration, 50, Suppl. 1, 26-30. 